\title{
Pre-participation Evaluation for Screening of Health Risks in Leisure and Young Competitive Athletes
}

\section{CARDIOLOGY / EXERCISE IS MEDICINE / PREPARTICIPATION / SPORTS AND SOCIETY / SPORTS MEDICINE}

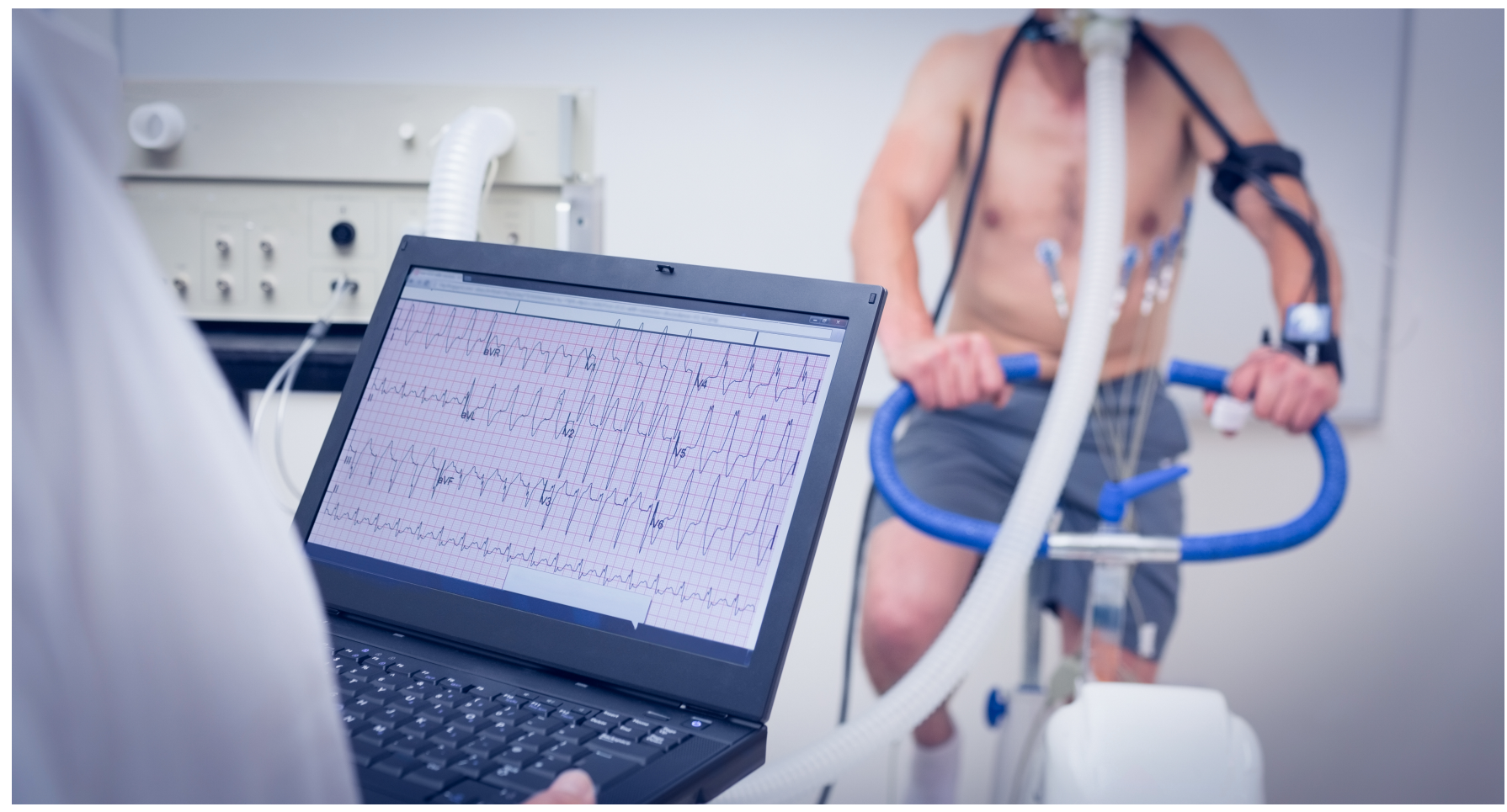

\section{Erat A}

Klinik Hirslanden, Witellikerstrasse 40, 8032 Zurich, Switzerland

\begin{abstract}
There seems to be a lack of consensus among medical associations, professional sports bodies and medical professionals about when pre-participation evaluations (PPE) are indicated and how they should be designed. Although it is generally accepted that the primary purpose of the PPE is the identification of cardiovascular disease and risk factors for sudden cardiac death in competitive athletes, there is an ongoing debate on which methods are most apt in the screening process. Furthermore, the need of PPE has been questioned all together in leisure or hobby athletes. Nevertheless, many recreational sportsmen or leisure athletes will seek advice from their medical providers before engaging in an exercise program, and competitive athletes may be required to undergo screening for underlying medical conditions and risk of
\end{abstract}


sudden cardiac death before each sports season (depending on the sports association and country of origin). It is therefore important for clinicians - and for sports doctors in particular - to be aware of current guidelines for identifying high-risk individuals who may require a more thorough evaluation before beginning an exercise program or before the game season. Hence, the objective is to review guidelines regarding PPE as a method for screening health risks, especially sudden cardiovascular death, prior to participation in exercise and sports. For an in-depth description and the SGSM Consensus refer to SSEM 2/2019.

\section{Zusammenfassung}

Es hat scheinbar einen fehlenden Konsens zwischen Medizinern, Medizingesellschaften und professionellen Sportverbänden, was die Notwendigkeit und das Design von sportmedizinischen Untersuchungen (pre-participation exam PPE) betrifft. Obwohl allgemein anerkannt ist, dass der Hauptgrund einer sportmedizinischen Untersuchung die Erhebung kardiovaskulärer Risikofaktoren ist, so gibt es doch eine anhaltende Diskussion, mit welchen Methoden das am besten geschehen kann. Weiter wurde der Nutzen von sportmedizinischen Untersuchungen bei Freizeit- und Hobbysportlern im Allgemeinen hinterfragt. Trotzdem suchen gerade diese Rat bei ihrem Arzt, bevor sie eine neue Sportart beginnen und Profis müssen ein regelmässiges Screening auf sich nehmen (meist zu Saisonstart, je nach Sportart und Herkunftsland). Dementsprechend ist es für Kliniker im Allgemeinen und Sportmedizinern im Besonderen wichtig, mit den aktuellen Richtlinien zur Identifikation von Hochrisiko- Patienten à jour zu sein. Denn diese brauchen oft eine detaillierte Untersuchung, bevor sie für einen neuen Sport oder eine neue Saison freigegeben werden können. Es ist daher die Aufgabe dieses Beitrags, die Guidelines betreffend sportmedizinischen Untersuchungen, speziell für plötzlichen Herztod, zu diskutieren. Für eine detaillierte Beschreibung und den SGSM Consensus siehe SSEM 2/2019.

\section{Introduction}

It is well known that regular exercise has a wide range of health benefits and that a sedentary lifestyle may be an even stronger predictor of mortality than hypertension, smoking and diabetes [1]. As many epidemiologic studies show, that sedentary individuals are two to three times more likely to die during follow-up compared with their sportive peers, clinicians should routinely assess and prescribe structured exercise to their patients.

However, for persons with an underlying cardiac disorder, the risk of sudden cardiac death (SCD) potentially increases with exercise both for competitive and leisure athletes. Naturally the risk is related to the severity of the underlying pathology and the level of exertion, and athletes under 35 years of age are significantly more likely to suffer a SCD from an underlying inherited structural heart disease (such as arrhythmogenic right ventricular cardiomyopathy and hypertrophic cardiomyopathy, congenital coronary artery anomalies, Marfan syndrome, etc) or an inherited arrhythmia syndrome (such as Brugada syndrome, long QT syndrome, etc) than elder sportsmen. Sportsmen over 35 years of age, on the other hand, are more likely to suffer from coronary heart disease (CAD). Yet, there seems to be a lack of consensus among organizations and clinicians about the extent of the medical evaluation needed for screening for the population as a whole [2], since there are several variables that must be considered in order to set up proper screening programs. These variables include 
athlete age, whether the athlete has known cardiovascular, metabolic, or renal disease, and on the intensity of the exercise as well as prior training history [3]. Hence, in this review, leisure athletes are distinguished from competitive athletes, and the guidelines are consequently addressed separately.

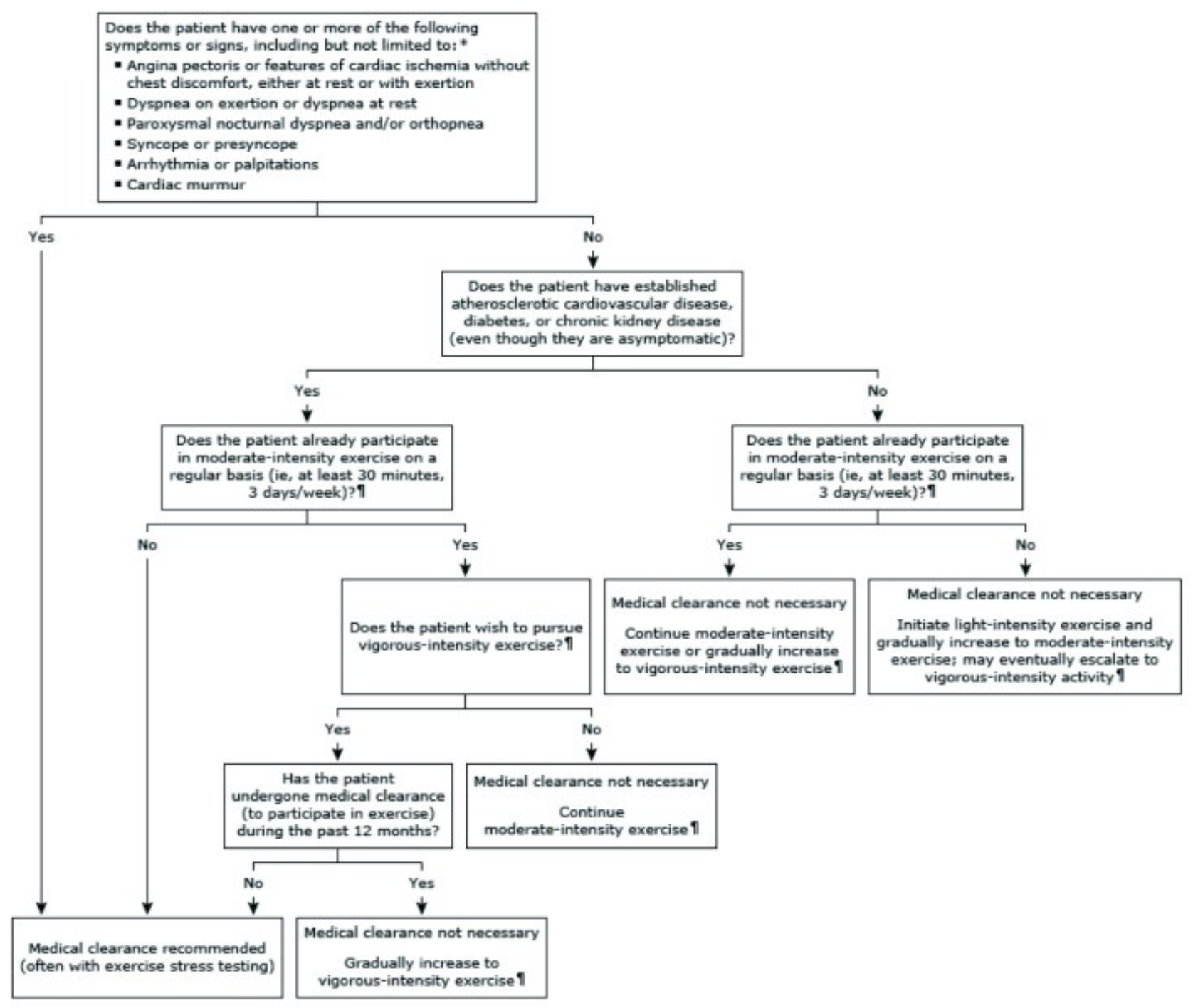

Figure 1: Screening algorithm for leisure athletes by the American College of Sports Medicine. Source: Adapted from: Riebe D, Franklin BA, Thompson PD, et al. Updating ACSM's Recommendations for Exercise Preparticipation Health Screening. Med Sci Sports Exerc 2015;47:2473.

\section{Guidelines for Leisure Athletes}

There is an increasing number leisure athletes that participates in marathon runs, thriatlon, biking competitions and vigorous exercise, including older persons, hobby sportsmen, beginners and returnees. As opposed to a competitive athletes that are young (usually $\leq 35$ years), leisure athletes are individuals, most frequently middle-aged/senior that participate in a variety of informal recreational sports, within a range of exercise levels, which do not require systematic training or the pursuit of excellence [6]. Although 
PPE potentially allows life-threatening cardiovascular abnormalities and other risk factors to be identified before onset of symptoms, there is a vigorous debate among healthcare professionals about efficacy, and cost-effectiveness, and impact of false-positive results of routine screening. Indeed the 2018 Physical Activity Guidelines for Americans promulgated by the US Department of Health and Human Services, state that asymptomatic persons without diagnosed chronic conditions (such as diabetes mellitus, heart disease, or osteoarthritis) do not need to consult a health care provider about physical activity [4,5]. Furthermore, since exercise is highly beneficial for the great majority of the population, and as there is considerable evidence that exercise is safe for most people, too restrictive PPE can be more harmful than beneficial in low risk groups, as they can create a barrier to exercise participation and result in excessive physician referrals.

Consequently, the American College of Sports Medicine's proposed a new, less restrictive and a more evidence-informed model for PPE in 2014 based of three factors:

1. the individual's current level of physical activity,

2. presence of signs or symptoms and/or known cardiovascular, metabolic, or renal disease, and

3. desired exercise intensity,

as these variables have been identified as risk modulators of exercise-related cardiovascular events. Even though the identifying of cardiovascular disease risk factors remains an important objective of overall disease prevention and management, the risk factor profiling is no longer included in the exercise PPE [7]. All together, exercise testing screening prior to initiating a vigorous exercise training should be only reserved to those asymptomatic individuals with an increased risk of coronary artery disease, assessed using available risk score according to the guidelines of the ACC/AHA, the American College of Sports Medicine and ESC. Clearly, symptomatic persons suffering from chest pain, shortness of breath, or of symptoms such as dizziness should be examined more closely [14]. The approach to screening is summarized in the Figure 1.

Guidelines for Young Competitive Athletes SCD is the leading cause of mortality in young athletes and it mainly results from undiagnosed electrical cardiovascular or structural disease as mentioned before [8,9]. SCD is associated with athletic activity and the affected are usually young and apparently healthy. It is true that the incidence is fairly low and varies widely from $0.5-2 / 100,000 /$ year [10,11], but the emotional consequences for the victims and their families are highly distressing. Whereas PPE is not always recommended in leisure athletes, most national and international bodies today agree that young competitive athletes should be screened for conditions predisposing them to SCD (Table 1).

The burning question here, however, is how the screening should be designed. In Italy, for instance, a 12lead ECG screening has long been a mandatory part of the PPE in addition to a physical examination and patient as well as family history [12]. Similarly, Israel and Luxemburg have also required screening with ECG [13]. In Switzerland, the PPE is widely based on the "Lausanne recommendations" from 2004, which is a consensus paper under the umbrella of the International Olympic Committee Medical Commission. The Lausanne Recommendations lay a strong emphasis on personal and family history, and a physical exam as well as an ECG. In addition, a blood exam as detailed by Swiss Olympic may also be added to the exam [15]. On a sport-discipline-specific level, several national sports associations require ECG to be part of the PPE, 
and both the ESC as well as the International Olympic Committee recommend an ECG for young competitive athletes (Figure 2).

The most significant difference between North American and European groups is that the American groups recommend a PPE with history using the AHA's 14-point questionnaire and physical examination alone, without a standard 12-lead electrocardiogram (ECG) [8,9]. Yet specific sports bodies may have specific requirements and recommevndations exceeding those of the American Heart Association (AHA) and American College of Cardiology (ACC). The National Basketball Association, for instance, even requires yearly exercise echocardiograms and Color Flow Doppler studies.

\section{Ref.}

Fuller et al.

Corrado et al.

Wilson et al.

Bessem et al.

Baggish et al.

\begin{tabular}{|l|l|}
\hline Population & Pr \\
\hline 5617 high school athletes (USA) & 0.4 \\
\hline 42,386 athletes age $12-35$ (Italy) & 0.2 \\
\hline 2720 athletes and children age $10-17$ (UK) & 0.3 \\
\hline 428 athletes age 12-35 (Netherlands) & 0.7 \\
\hline 510 collegiate athletes (USA) & 0.6 \\
\hline
\end{tabular}

\section{Prevalence [\%]} 0.4

0.6

Table 1: Prevalence of cardiovascular diseases at risk for sudden cardiovascular death in young athletes. Source: Adopted from Corrado D, Schmied C, Basso C, Borjesson M, Schiavon M, Pelliccia A, et al. Risk of sports: do we need a pre-participation screening for competitive and leisure athletes? Eur Heart J. 2011;32(8):934-44.

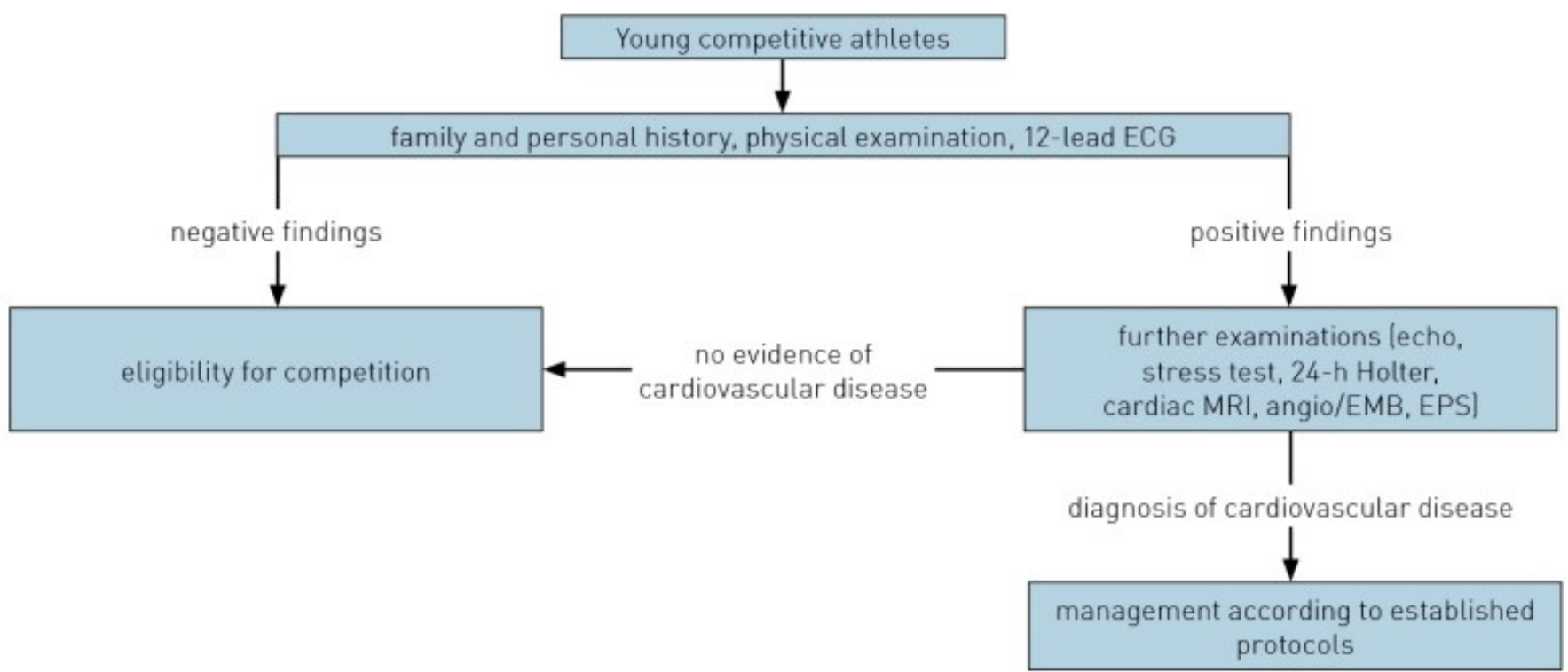

Figure 2: Flow diagram illustrating the modality of pre-participation

cardiovascular screening recommended by the European Society of Cardiology section of Sports Cardiology.

Source: Adapted from Corrado D, Schmied C, Basso C, Borjesson M, Schiavon M, Pelliccia A, et al. Risk of sports: do we need a pre-participation screening for competitive and leisure athletes? Eur Heart J. 2011;32(8):934-44. 


\section{The way forward}

PPEs that include clinical history (at least patient history and family history), physical examination, and 12-lead ECG, have shown to be superior in diagnostic capability than just clinical history and physical examination. It is likely, that PPEs including a 12-lead ECG can better identity arrhythmogenic conditions at risk (cardiomyopathies and channelopathies), and do therefore have higher diagnostic power (Figure 3 and 4).

Yet, there are challenges to widespread screening particularly in leisure athletes, including costeffectiveness. The large (and increasing) number of leisure and competitive athletes alike, with millions of high school athletes in the United States alone, and the low prevalence of underlying heart disease, clearly compose an economical challenge. Research should therefore pave the way for a better identification of individuals at risk, and more innovative screenings should be welcomed. One such innovative approach could be the On-Site prevention and education to improve cardiac pre-competition screening introduced at the Swiss Alpine Marathon in Davos, in Switzerland [16].

In addition, the impact of test sensitivity and specificity and the implications of false positive or false negative results cannot be underestimated for both leisure and competitive athletes. Yet the improved criteria to interpret the ECG in athletes, including the Seattle criteria to improve specificity, are increasingly important in both accomplished by better identification, but also more accurate risk stratification allowing a lower burden of sport disqualification.

Furthermore, the risk stratification may in the future be based on novel non-invasive techniques that identify i.e. coronary artery abnormalities and subclinical CAD, in addition to age and the anticipated level of activity. Such developments would likely reduce costs and increase efficiency, and ultimately also have an impact on consensus forming and guidelines. 


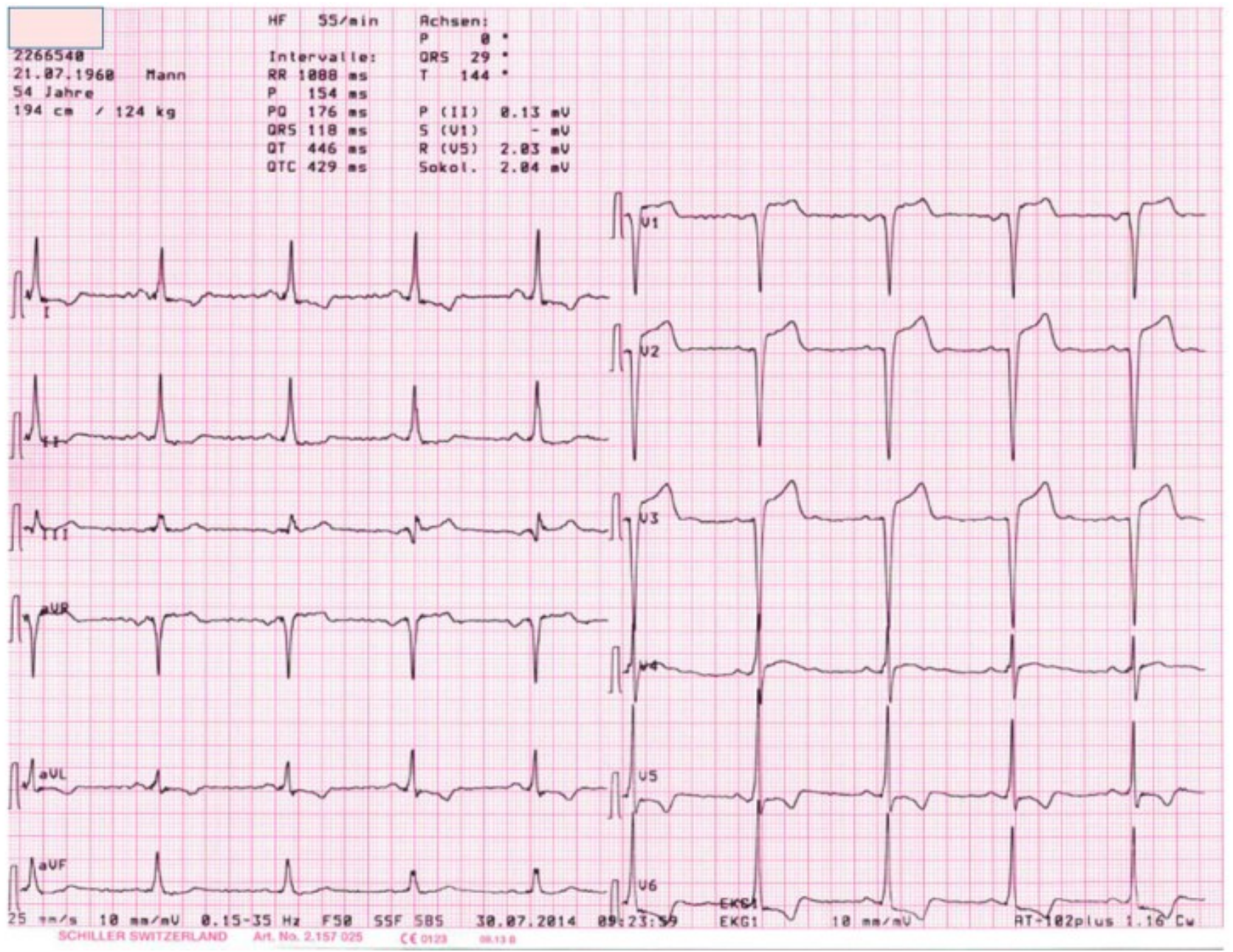

Figure 3: Hypertrophic cardiomyopathy (HCM) is caused by autosomal dominant mutations in cardiac sarcomere protein genes in the majority of adolescents and adults affected by the myopathy. HCM is defined by the presence of increased left ventricular (LV) wall thickness that is not exclusively due by abnormal loading conditions. The standard

12-lead ECG can show a variable combination of pathological Q-waves, large QRS voltage, ST- and T-wave abnormalities as shown below. For the diagnosis and monitoring HCM, however, echocardiography is crucial. 


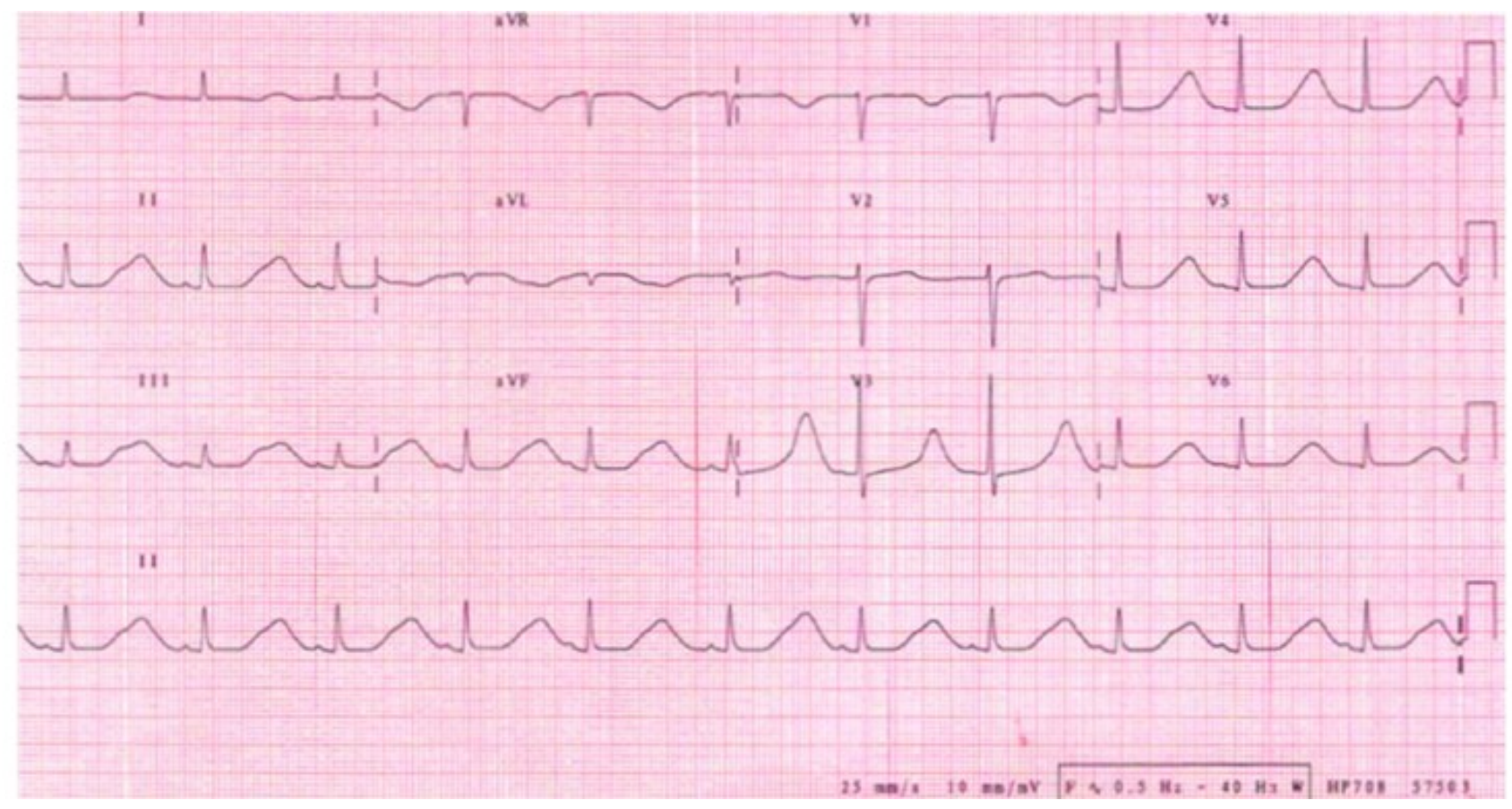

Figure 4: Figure 4 shows an ECG of a patient with long QT syndrome, a condition affecting repolarization and responsible for palpitations, fainting or sudden cardiac death after exercise or stress. According to the European Society of Cardiology, LQTS can be diagnosed if the corrected QT duration is larger than 480 ms in repeated 12-lead ECG, in the presence of a confirmed pathogenic LQTS mutation, irrespective of the QT duration, or in cases of a high LQTS risk score (3 points) based on ECG, clinical symptoms such as syncope, and on family history.

\section{Conflict of interest and funding}

None declared.

\section{Corresponding author}

Anna Erat, MD/PhD

Klinik Hirslanden

Witellikerstrasse 40

8032 Zurich

Switzerland

+41 (0)434992030

anna.erat@hirslanden.ch

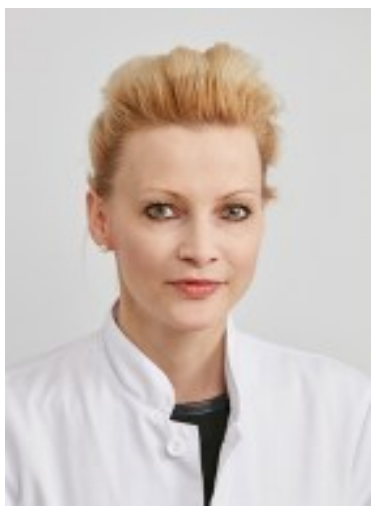

\section{References}

1. Ross R, Blair SN, Arena R, Church TS, Després JP et. al. Importance of Assessing Cardiorespiratory Fitness in Clinical Practice: A Case for Fitness as a Clinical Vital Sign: A Scientific Statement From the 
American Heart Association. Circulation. 2016;134(24):e653. Epub 2016 Nov 21.

2. American College of Sports Medicine. ACSM's Guidelines for Exercise Testing and Prescription, 9th ed, Lippincott Williams \& Wilkins, Baltimore 2013.

3. Thompson PD, Franklin BA, Balady GJ, et al. Exercise and acute cardiovascular events placing the risks into perspective: a scientific statement from the American Heart Association Council on Nutrition, Physical Activity, and Metabolism and the Council on Clinical Cardiology. Circulation 2007;115:2358.

4. Piercy KL, Troiano RP, Ballard RM, et al. The Physical Activity Guidelines for Americans. JAMA 2018;320:2020.

5. 2018 Physical Activity Guidelines for Americans, 2nd edition, United States Department of Health and Human Services https://health.gov/paguidelines/second-edition/pdf/Physical_Activity_Guidelines_ 2nd_edition.pdf (Accessed on December 11, 2018).

6. Maron BJ, Chaitman BR, Ackerman MJ, Baye's de Luna A, Corrado D, Crosson JE, Deal BJ, Driscoll DJ, Estes NA III, Arau'jo CG, Liang DH, Mitten MJ, Myerburg RJ, Pelliccia A, Thompson PD, Towbin JA, Van Camp SP; Working Groups of the American Heart Association Committee on Exercise, Cardiac Rehabilitation, and Prevention; Councils on Clinical Cardiology and Cardiovascular Disease in the Young. Recommendations for physical activity and recreational sports participation or young patients with genetic cardiovascular diseases. Circulation 2004;109:2807-2816.

7. Riebe D, Franklin BA, Thompson PD, Garber CE, Whitfield GP, Magal M, Pescatello LS. Updating ACSM's Recommendations for Exercise Preparticipation Health Screening. Med Sci Sports Exerc. 2015; 47(11):2473.

8. Maron BJ, Thompson PD, Ackerman MJ, et al. Recommendations and considerations related to preparticipation screening for cardiovascular abnormalities in competitive athletes: 2007 update: a scientific statement from the American Heart Association Council on Nutrition, Physical Activity, and Metabolism: endorsed by the American College of Cardiology Foundation. Circulation 2007;115:1643.

9. Maron BJ, Thompson PD, Puffer JC, et al. Cardiovascular preparticipation screening of competitive athletes. A statement for health professionals from the Sudden Death Committee (clinical cardiology) and Congenital Cardiac Defects Committee (cardiovascular disease in the young), American Heart Association. Circulation 1996;94:850.

10. Maron BJ, Thompson PD, Puffer JC, et al. Cardiovascular preparticipation screening of competitive athletes: addendum: an addendum to a statement for health professionals from the Sudden Death Committee (Council on Clinical Cardiology) and the Congenital Cardiac Defects Committee (Council on Cardiovascular Disease in the Young), American Heart Association. Circulation 1998; 97:2294.

11. Maron BJ, Araújo CG, Thompson PD, et al. Recommendations for preparticipation screening and the assessment of cardiovascular disease in masters athletes: an advisory for healthcare professionals from the working groups of the World Heart Federation, the International Federation of Sports Medicine, and the American Heart Association Committee on Exercise, Cardiac Rehabilitation, and Prevention. Circulation 2001;103:327.

12. Corrado D, Basso C, Pavei A, et al. Trends in sudden cardiovascular death in young competitive athletes after implementation of a preparticipation screening program. JAMA 2006;296:1593-601.

13. Steinvil A, Chundadze T, Zeltser D, et al. Mandatory electrocardiographic screening of athletes to reduce their risk for sudden death proven fact or wishful thinking? J Am Coll Cardiol 2011;57:1291-6.

14. Corrado D, Schmied C, Basso C, Borjesson M, Schiavon M, Pelliccia A, et al. Risk of sports: do we need a pre-participation screening for competitive and leisure athletes? Eur Heart J. 2011;32(8):934-44.

15. https://www.swissolympic.ch/ueber-swiss-olympic/partner_labelin haber/medizinische-institutionen.html?tabId=8bac170b-9f61-461d-86b2-0912787a76b9, retrieved 30 June 2019.

16. Schwotzer R, Kistler W, Keller DI, Wolber T, Lüscher TF, Drechsel S, Villiger B, Schmied C. «On-site» 
prevention and education to improve cardiac precompetition screening in competitive amateur athletes. Swiss Med Wkly. 2013 May 7;143:w13785.

\author{
COMPETITIVE ATHLETE ATHLETE ECG HEALTH RISKS LEISURE ATHLETE PRE-PARTICIPATION \\ EVALUATION (PPE) SPORTS MEDICAL SCREENING SUDDEN CARDIAC DEATH (SCD)
}

